\title{
Commentary: Open hemi-arch replacement in bicuspid aortic valve aortopathy without arch dilatation? If it's not broken, no need to fix it!
}

\author{
Francois Dagenais, MD
}

\footnotetext{
From the Department of Cardiac Surgery, Institut Universitaire de Cardiology et Pneumologie de Québec, Québec, Québec, Canada.

Disclosures: Author has nothing to disclose with regard to commercial support.

Received for publication Sept 17, 2019; revisions received Sept 17, 2019; accepted for publication Sept 17, 2019; available ahead of print Oct 3, 2019.

Address for reprints: Francois Dagenais, MD, Institut Universitaire de Cardiology et Pneumologie de Québec, 2725 chemin Sainte-Foy, Québec, Québec, Québec, Canada G1V4G5 (E-mail: francois.dagenais@chg. ulaval.ca).

J Thorac Cardiovasc Surg 2021;161:23-4

0022-5223/\$36.00

Copyright (C) 2019 by The American Association for Thoracic Surgery

https://doi.org/10.1016/j.jtcvs.2019.09.103
}

In the current issue of the Journal, Greason and colleagues ${ }^{1}$ report an interesting study comparing an open hemi-arch replacement (OHAR) with a clamped ascending aortic replacement (CAAR) as a distal aortic repair strategy in patients with bicuspid aortic valve aortopathy. The authors reviewed 702 consecutive patients operated for a nonemergent bicuspid aortic valve replacement between 2000 and 2017 receiving either a CAAR $(n=477)$ or an OHAR $(\mathrm{n}=225)$. The OHAR was conducted under deep hypothermia $\left(18^{\circ} \mathrm{C}\right)$ with adjunctive cerebral perfusion in $28 \%$ of cases. The decision to perform an OHAR or a CAAR was surgeon based. Mean aortic arch diameter measured at the level of the left common carotid artery was nondilated and similar in both groups (CARR: $33 \mathrm{~mm}$ vs OHAR: $34 \mathrm{~mm} ; P=.13$ ). Perioperative morbidity was low for both operative strategies. A significantly greater transfusion rate was observed in the OHAR group $(64 \%$ vs $56 \% ; P=.038)$, whereas an increased risk of reoperation for bleeding was seen in the CAAR group $(5 \%$ vs $1 \% ; P=.017)$. At a mean follow-up of 5.4 years, no patient required reoperation for late aneurysmal arch degeneration. Survival was comparable for both groups. The authors conclude that in the absence of arch dilatation, an open hemi-arch replacement offers no advantage over a clamped ascending aorta replacement.

Greason and colleagues raise a yet-unresolved debate on the extent of distal resection in patients with bicuspid aortic valve aortopathy. It is well known that bicuspid aortopathy may involve the aortic arch while sparing the descending aorta. ${ }^{2}$ To minimize the risk of late arch aneurysmal degeneration, some authors have promoted an aggressive approach to perform an OHAR even in the absence of a dilated arch. ${ }^{3}$ Although OHAR can be carried out with excellent operative outcomes, no current evidence supports that such an extended procedure may decrease

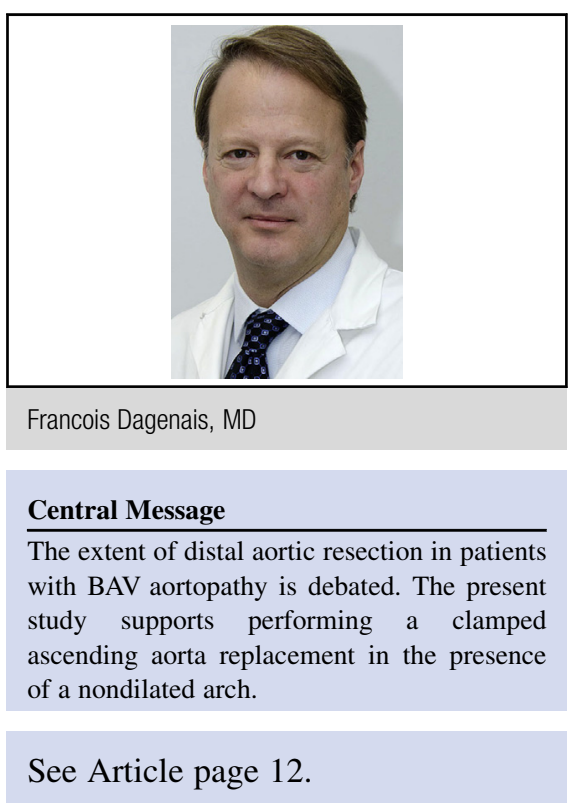

late arch reintervention or increase survival compared with a CAAR in a nondilated arch bicuspid valve aortopathy. The study by Greason and colleagues supports these findings.

However, study limitations have to be outlined. In $26 \%$ of cases, arch measurements were not available, whereas $47 \%$ of arch measurements were obtained by echocardiography, oftentimes less accurate in the arch. Although no reoperation for arch dilatation was observed in both groups, arch measurements at follow-up were not reported. The follow-up period of 5.4 years remains limited in this population with good life expectancy and may lack identifying aortic degeneration at a later time point. Moreover, other variables such as bicuspid valve phenotypes, presence of aortic stenosis or regurgitation, and genetic factors such as the NOTCH gene have been associated with bicuspid valve aortopathy. ${ }^{4,5}$ Further investigation may identify specific predictors influencing growth and extent of aortic degeneration in bicuspid aortic valve aortopathy. Until then, as supported by the present study, a clamped ascending aorta replacement should be performed in bicuspid aortic valve aortopathy without arch dilatation. In the presence of proximal arch dilatation $(>4.5 \mathrm{~cm})$, an open hemiarch aorta replacement 
may be accomplished with excellent results in centers of expertise.

\section{References}

1. Greason KL, Crestanello JA, King KS, Bagameri G, Cicek SM, Stulak JM, et al Open hemiarch versus clamped ascending aorta replacement for aortopathy during initial bicuspid aortic valve replacement. J Thorac Cardiovasc Surg. 2021;161: 12-20.e2.

2. Kari FA, Fazel SS, Mitchell RS, Fischbein MP, Miller DC. Bicuspid aortic valve configuration and aortopathy pattern might represent different pathophysiological substrates. J Thorac Cardiovasc Surg. 2012;144:516-7.

3. Singh R, Yamanaka K, Reece TB. Hemiarch: the real operation for ascending aortic aneurysm. Semin Cardiothorac Vasc Anesth. 2016;20:303-6.

4. Lenihan M, Vegas A, Buys M, Mashari A, Feindel C, Djaiani G. Re: "Bicuspid Aortic Valve Associated Aortopathy: a Primer for Cardiac Anaesthesiologists" J Cardiovasc Vasc Anesth. September 25, 2019 [Epub ahead of print].

5. Jiao J, Tian W, Qiu P, Norton EL, Wang MM, Chen YE, et al. Induced pluripotent stem cells with NOTCH1 gene mutation show impaired differentiation into smooth muscle and endothelial cells: implications for bicuspid aortic valverelated aortopathy. J Thorac Cardiovasc Surg. 2018;156:515-22. 